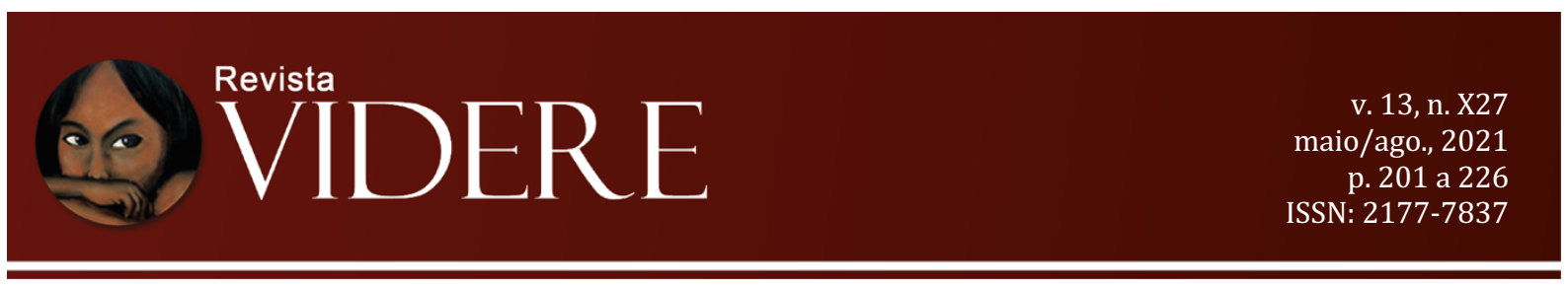

\title{
TRABALHO DECENTE: CONSOLIDAÇÃO HISTÓRICA POR INTERMÉDIO DA ORGANIZAÇÃO INTERNACIONAL DO TRABALHO (OIT)
}

\author{
DECENT WORK: HISTORICAL CONSOLIDATION THROUGH THE \\ INTERNATIONAL LABOR ORGANIZATION (ILO)
}

\author{
TRABAJO DECENTE: CONSOLIDACIÓN HISTÓRICA A TRAVÉS DE LA \\ ORGANIZACIÓN INTERNACIONAL DEL TRABAJO (OIT)
}

Lucilaine Ignacio da Silva Doutora em Direito pela Universidade Federal de Santa Catarina - UFSC

Docente na Universidade do Vale do Itajaí - UNIVALI lucilaine@gmail.com

OrcidID: https://orcid.org/0000-0002-9396-7557

\begin{abstract}
Joana Stelzer
Doutora em Direito pela Universidade Federal de Santa Catarina (UFSC) Professora Associada II/UFSC na Pós-Graduação em Direito (PPGD)

joana.stelzer@ufsc.br OrcidID: https://orcid.org/0000-0002-9503-4080
\end{abstract}

Resumo: O Trabalho Decente e a Dignidade Humana confundem-se ao longo da história e, usualmente, demandam esforços axiológicos para o devido enquadramento. Tal circunstância também trouxe impasses na construção normativa da Organização Internacional do Trabalho (OIT) e na sua relação com Estados-membros. O objetivo geral do presente artigo consiste em evidenciar a trajetória do conceito de Trabalho Decente no âmbito da OIT, percorrendo etapas específicas como descrever a tese da internacionalização do Direito do Trabalho, evidenciar a construção do conceito de trabalho decente e identificar possibilidades de acesso ao trabalho decente. Trata-se de pesquisa pura, de abordagem qualitativa e indutiva. Em relação aos fins, utilizou-se o método descritivo. Quanto aos resultados, verifica-se que não há convergência entre as diretrizes da OIT e os valores defendidos por integrantes (especialmente empregadores), o que dificulta a promoção do emprego de qualidade.

Palavras-chave: Organização Internacional do Trabalho (OIT). trabalho decente. dignidade humana. 
Abstract: Decent Work and Human Dignity have become confused throughout history and usually require axiological efforts for proper framing. This circumstance has also brought impasses to the normative construction of the International Labor Organization (ILO) and in its relationship with Member States. The general objective intends to highlight the trajectory of the concept of Decent Work within the ILO. The specific objectives consist of: to describe the thesis of the internationalization of Labor Law through the ILO, to show formative aspects in the construction of the concept of decent work and to identify access routes to decent work. It is a pure research, with a qualitative and inductive approach. In relation to the ends, the descriptive method was used. As for the results, it appears that there is no convergence between the ILO guidelines and the values defended by some members (especially employers), which makes it difficult to promote quality employment.

Keywords: International Labor Organization (ILO). decent work. human dignity.

Resumen: El trabajo decente y la dignidad humana se han confundido a lo largo de la historia y suelen exigir esfuerzos axiológicos para su ajuste. Esta circunstancia también trajo una desavenencia en la construcción normativa de la Organización Internacional del Trabajo (OIT) y su relación con los Estados Miembros. El objetivo general de este artículo es resaltar la trayectoria del concepto de Trabajo Decente dentro de la OIT, pasando por etapas específicas como describir la tesis de la internacionalización del Derecho Laboral, evidenciar la construcción del concepto de trabajo decente e identificar posibilidades accederlo. Se trata de investigación pura, con enfoque cualitativo e inductivo. En relación a los fines, se utilizó el método descriptivo. A respecto de los resultados, se verifica que no existe convergencia entre las directrices de la OIT y los valores defendidos por los Miembros (especialmente los empleadores), hecho que dificulta la promoción del empleo de calidad.

Palabras clave: Organización Internacional del Trabajo (OIT). trabajo decente. dignidad humana.

\section{Introdução}

A legislação trabalhista contemporânea é uma conquista de séculos, que demandou aprimoramento e equanimidade entre os atores envolvidos ao longo do tempo para que o exercício laboral pudesse viabilizar, com dignidade, a construção material e espiritual do Planeta. Nesse sentido, emergiu a contribuição da Organização Internacional do Trabalho (OIT), articulando as relações institucionais em ambientes político-econômicos os mais diversos, seja no pós-guerra, nas crises econômicas ou nas distintas oscilações históricas que já marcaram o cenário mundial.

Embora o ambiente externo sempre tenha sido marcado por países com diversidade cultural, religiosa, econômica, política ou jurídica, sob a batuta da OIT reconheceram-se avanços significativos. Naturalmente, é imperioso reconhecer quantos limites já se impuseram aos esforços da OIT e que continuam demandando ações integradas e estudos para que se possa 
evoluir em conjunto. Sob tal ótica, inclui-se o aprimoramento do denominado Trabalho Decente.

O Trabalho Decente e o próprio entendimento sobre o que seja Dignidade Humana demandam esforços axiológicos para o devido enquadramento, circunstâncias que têm trazido impasses ao longo da história da OIT. Com base nessa delimitação, o presente estudo justificase na dificuldade internacional em consolidar essa compreensão por parte da OIT e dos demais agentes envolvidos (empregadores, Estados-membros, ente outros). Além do mais, o fato de a OIT ser privada em impor a obrigatoriedade de suas normas, ainda mais enfraquece essa proposta.

Sob tal escopo, o objetivo geral consiste em evidenciar a trajetória do conceito de Trabalho Decente no âmbito da OIT, o que será feito a partir dos seguintes objetivos específicos: descrever a tese da internacionalização do Direito do Trabalho por intermédio da OIT; evidenciar aspectos de formação na construção do conceito de trabalho decente; e, identificar as vias de acesso ao trabalho decente a partir das estratégias promovidas pela OIT.

Quanto aos estudos que serviram para abalizar o marco teórico, merece destaque a própria documentação da OIT que retratou de forma histórica as filigranas da construção normativa abalizadora das suas Resoluções e Declarações. Sob tal senda, notadamente as reflexões de Laís Abramo e de Juan Somavía apoiaram a pesquisa.

No que tange à metodologia, quanto à natureza, trata-se de pesquisa pura, pois houve foco em decifrar os caminhos trilhados pela OIT no que se refere à consolidação do Trabalho Decente. Quanto à abordagem do problema, trata-se de estudo qualitativo orientado precipuamente por textos históricos, doutrina e o corpo de normas da Organização. Quanto aos fins, é descritiva, no afã de apontar os aspectos relevantes da compreensão hodierna do que seja dignidade nas relações laborais. O método de abordagem é o indutivo crítico, embora não se possa assegurar avanço progressivo e uniforme da OIT na empreitada rumo ao Trabalho Decente. Ainda assim, diante da complexidade do processo, o referido método é útil, na medida em que permite o desenlace das situações passadas e contemporâneas. Quanto ao método de interpretação é precipuamente gramatical; mas, também lógico-sistemático, à medida que buscou contemplar as demandas da sociedade internacional e a necessidade de disciplina hábil a fornecer resposta a seu tempo. Quanto aos procedimentos técnicos, é doutrinário e documental. Os resultados são apresentados em forma de texto. 


\section{A tese da internacionalização do Direito do Trabalho e a criação da Organização Internacional Do Trabalho (OIT)}

A OIT, desde sua gênese, espelhou a criação de um padrão de normas de trabalho, que pudesse ser homogêneo e alcançar diversos Estados. A premência em alcançar o equilíbrio entre trabalhadores e patrões engendrava limites e condições mínimas de relacionamento. Além do mais, o avanço do capitalismo também pressionava por regramento nas relações laborais. Não podendo se equiparar força de trabalho à mercadoria, a dignidade da pessoa humana clamava por disciplina que protegesse a essência do ser, embora houvesse ciência acerca do necessário entrelaçamento com o sistema econômico.

O reconhecimento da tese de internacionalização das normas de proteção do trabalho - de acordo com Süssekind (1998, p. 18) - foi reivindicado em vários congressos, com destaque para o Congresso Trabalhista de Lyon (1877), Congresso Socialista de Paris (1889), Congressos de Leeds (1916), Estocolmo (1917), Búfalo (1917) e Congresso de Berna (1919) e, mesmo durante a I Guerra Mundial, a questão foi tratada com relevância. Afirmar que a tese de internacionalização do Direito do Trabalho resumia-se a simples harmonização de normas nacionais preexistentes, com o intuito de facilitar as transações internacionais é equivocado, pois foi além, representando - em verdade - condição indispensável à preservação dessas legislações. Contudo, interessa compreender as ideias e os ideais que sustentaram e levaram à criação de legislação trabalhista internacional, afinal, já havia registros acerca de tentativas de unificação normativa, porém, muitas sem sucesso ${ }^{1}$.

O Tratado de Versailles celebrado sob a presidência de Samuel Gompers, com a participação de representantes dos empresários e dos trabalhadores na assembleia e no órgão colegiado de administração, universalizou os princípios fundamentais da Organização Internacional do Trabalho, compondo o artigo I do Anexo da Constituição da OIT. Era o coroamento de esforços anteriores:

A verdade é que a tese de internacionalização das normas de proteção do trabalho já havia obtido expressiva ressonância quando a Conferência da Paz se instalou no Palácio de Versailles. Lançada pelo industrial socialista da GrãBretanha Robert Owen (1818), ampliada pelo professor de Sorbonne Louis

\footnotetext{
${ }^{1}$ Registra-se que em 1900, um dos precursores da OIT, a Associação Internacional para Legislação do Trabalho (IAL), uma organização não-governamental, fundada na Basileia, tentou influenciar os governos a adotar leis que limitassem o trabalho noturno das mulheres e proibisse o fósforo branco, substância química potencialmente perigosa usada na fabricação de fósforos (ILO, 2018a, $\mathrm{n} / \mathrm{p}$ ).

Esforço de guerra, em política e planejamento militar, refere-se a uma mobilização social coordenada de recursos industriais e humanos visando ao suporte de uma força militar.
} 
Blanqui (1838), defendida pelo industrial alsaciano Daniel Legrand (1841), incluída no Manifesto socialista de Marx e Engels (1848) e advogada pelo Papa Leão XIII na Encíclica Rerum Novarum (1891), inúmeros foram os conclaves que sobre o tema realizaram. No âmbito governamental, cumpre destacar o Congresso de Berlim (1890) e as Conferências de Berna (1905, 1906 e 1913), dos quais resultaram as primeiras convenções do trabalho (SÜSSEKIND, 1998, p. 18).

Por certo, inovações tecnológicas como a invenção da máquina a vapor, revolucionaram não só o mundo do trabalho como a sociedade de modo geral, motivo que levou a OIT “[...] desde o seu nascedouro, expressar preocupação com o equilíbrio das relações capital-trabalho, buscando proteger o trabalhador da opressão do poderio econômico e estabelecendo normas internacionais com vistas a repelir condições laborais degradantes" (AZEVEDO NETO, 2015, p. 55).

Importante registrar que o período antecessor à criação e formação da OIT foi marcado pelo flagelo da I Guerra Mundial, cujas condições de trabalho pioraram significativamente e as leis trabalhistas foram frequentemente suspensas. Foi período no qual os trabalhadores passaram a reivindicar compensação pelo esforço de guerra ${ }^{2}$, bem como pela exploração da mão de obra.

No ano de 1948, dois anos após a Declaração de Filadélfia, a Declaração Universal dos Direitos Humanos pactuou com os princípios fundantes da OIT e assegurou em seu art. 23 que a toda e qualquer pessoa devem ser garantidas condições justas e favoráveis de trabalho, incluindo remuneração satisfatória, bem como, existência compatível com a dignidade humana:

1 Todo ser humano tem direito ao trabalho, à livre escolha de emprego, a condições justas e favoráveis de trabalho e à proteção contra o desemprego. 2 Todo ser humano, sem qualquer distinção, tem direito a igual remuneração por igual trabalho. 3 Todo ser humano que trabalha tem direito a uma remuneração justa e satisfatória que lhe assegure, assim como à sua família, uma existência compatível com a dignidade humana e a que se acrescentarão, se necessário, outros meios de proteção social. 4 Todo ser humano tem direito a organizar sindicatos e a neles ingressar para proteção de seus interesses (ILO, 2018c, n/p).

No enunciado da mencionada norma internacional verificou-se o prenúncio do que seria convencionado a se chamar de Trabalho Decente pela OIT, ao fazer deferência a questões como: condições justas e favoráveis de trabalho, não discriminação, rechaça às condições deploráveis e incompatíveis com a dignidade humana e liberdade sindical.

\footnotetext{
${ }^{2}$ Esforço de guerra, em política e planejamento militar, refere-se a uma mobilização social coordenada de recursos industriais e humanos visando ao suporte de uma força militar.
} 
Ressalta-se que as questões levantadas na referida Declaração de 1948 podem ter sido reflexo do discurso pronunciado pelo Presidente dos Estados Unidos da América (EUA), Franklin Delano Roosevelt, em janeiro de 1941. Em seu discurso sobre o Estado da União, conhecido como Discurso das Quatro Liberdades, o presidente descreveu as liberdades fundamentais de que todas as pessoas devem gozar: liberdade de expressão, liberdade religiosa, liberdade de viver sem penúria e liberdade de viver sem medo. Posteriormente, esses quatro conceitos influenciaram a redação da Carta das Nações Unidas e foram considerados direitos humanos universais (ILO, 2018a, n/p).

A OIT, no período compreendido entre 1948 a 1970, estava sob a Direção geral de David Morse que ampliou consideravelmente o escopo de ação da Organização, desenvolvendo a cooperação técnica como novo campo de atividade no difícil contexto da Guerra Fria. Sobre o período mencionado acima, que se caracterizou por mudanças contínuas, Morse (ILO, 2018b, n/p) recorda: “[...] Minha tarefa era reconstruir uma organização que havia sido derrotada durante a Segunda Guerra Mundial. Ela sobreviveu, o que foi um feito, mas ainda não havia encontrado uma base firme no mundo do pós-guerra".

Em 1969, o Programa Mundial de Emprego foi lançado. Morse colocou uma prioridade alta neste programa, como na sua opinião, desemprego e subemprego eram uma causa principal de pobreza e um obstáculo sério a desenvolvimento. Nos países em desenvolvimento, o desemprego atingiu enormes proporções e, mesmo quando o desenvolvimento econômico foi considerado bem-sucedido por critérios como o aumento do produto interno bruto, não conseguiu resolver o problema da criação de emprego produtivo para a crescente força de trabalho. O Programa Mundial de Emprego representou uma primeira tentativa de planejamento mundial no campo do desenvolvimento de recursos humanos e da política de emprego. (ILO, 2018b, $\mathrm{n} / \mathrm{p})$.

Por ocasião da Guerra Fria, novos Estados procuraram aderir à OIT que precisou se adaptar às emergentes necessidades. Afinal, o período que se estendeu de 1947 até fins da década de 1980 foi essencialmente marcado por conflitos de ordem política, econômica e ideológica entre as nações que emergiram fortalecidas ao término da Segunda Guerra Mundial (EUA e União das Repúblicas Socialistas Soviéticas - URSS). Sob outro aspecto, o processo de descolonização nos países periféricos assombrava com o crescimento da pobreza. Um “"[...] diálogo foi iniciado para adaptar a estrutura constitucional da OIT às novas demandas, o que levou, em última instância, a várias emendas constitucionais” (ILO, 2018a, n/p).

Os programas da Organização foram adaptados e tornaram-se mais flexíveis para se manterem universais. "Em 1946, a OIT tornou-se uma agência especializada das recém- 
formadas Nações Unidas" (ILO, 2018a, n/p). O reconhecimento público [da Organização] foi consagrado pela atribuição do Prémio Nobel da Paz em 1969, quando a OIT celebrou o seu 50 aniversário.

Na qualidade de agência especializada da Organização das Nações Unidas (ONU) a OIT, desde sua concepção, teve e tem, por missão, promover oportunidades para que homens e mulheres possam acessar um Trabalho Decente.

Em 1998, na Declaração da OIT sobre os Princípios e Direitos Fundamentais no Trabalho, os respectivos assuntos deveriam ser respeitados e promovidos pelos PaísesMembros independentemente de terem ratificado ou não as Convenções: a) a liberdade sindical e o reconhecimento efetivo do direito de negociação coletiva; b) a eliminação de todas as formas de trabalho forçado ou obrigatório; c) a abolição efetiva do trabalho infantil; e d) a eliminação da discriminação em matéria de emprego e ocupação. Rildo Brito (2011, p. 37) salientou que se tratava de "[...] iniciativa ousada da OIT para combater as piores formas de exploração no trabalho e se baseia na premissa de que há certos direitos básicos inerentes aos seres humanos e uma sociedade decente, mesmo que eles não tenham sido objeto de lei formal." Paradoxalmente, preconizava-se, a defesa dos Direitos e princípios do Trabalho na OIT em meio ao Consenso de Washington:

\footnotetext{
É importante notar que a Declaração dos Direitos e Princípios Fundamentais no Trabalho foi adotada em um momento caracterizado pelo auge do Consenso de Washington e em que predominavam as ideias relacionadas ao fim do trabalho, à desidratação dos sujeitos coletivos associados ao mundo do trabalho e à própria noção de que este pudesse ser um locus significativo de constituição de identidades e sujeitos coletivos. Um momento em que era visto como quase inevitável a diminuição ou a desaparição progressiva do trabalho formal, protegido, estável, regulado, devido tanto ao processo de desenvolvimento tecnológico, que produzia um desemprego estrutural, como ao processo de globalização que, ao acirrar a competitividade entre as empresas e os países, tornaria necessário e inevitável reduzir os custos do trabalho como parte dos custos da produção (ABRAMO, 2015, p. 25).
}

Assim, em 1999, o chileno Juan Somavía, Diretor Geral da OIT, durante a $87^{\mathrm{a}}$ Conferência Internacional do Trabalho, formalizou o termo Trabalho Decente - Decent Work, em inglês, que passou a significar o ponto de convergência dos quatro objetivos estratégicos da OIT: a liberdade sindical e reconhecimento efetivo do direito de negociação coletiva; a eliminação de todas as formas de trabalho forçado; a abolição efetiva do trabalho infantil; e, a eliminação de todas as formas de discriminação em matéria de emprego e ocupação, a promoção do emprego produtivo de qualidade, a proteção social e o fortalecimento do diálogo 
social (ILO, 2018a, n/p). Na oportunidade, o Diretor Geral enfatizou a importância do termo Trabalho Decente como objetivo internacional estratégico na promoção de uma globalização justa.

\title{
3 Formação do conceito de Trabalho Decente
}

A internacionalização do trabalho perpassou o esforço histórico do processo de formação do conceito de Trabalho Decente da OIT e envolveu fatos de natureza cultural, social, política e econômica, ou seja, em diversos aspectos da sociedade com reflexo no mundo do trabalho. A formação do conceito de Trabalho Decente já tinha tomado forma a partir de pontos estratégicos dispostos na Declaração de Filadélfia (1946), na Declaração Universal dos Direitos Humanos (1948), na Declaração da OIT sobre os Princípios e Direitos Fundamentais no Trabalho (1998) e na Declaração sobre Justiça Social por uma Globalização Equitativa (2008).

Süssekind (1998, p. 20) assinala que “[...] a característica mais importante da revisão constitucional de 1946 foi a incorporação ao Estatuto Básico, como anexo, da 'Declaração Referente aos Fins e Objetivos da Organização Internacional do Trabalho', [...]." Tal intento conferiu status hierárquico constitucional à Declaração de Filadélfia (1944) que ratificou a ideia de cooperação internacional na consecução da segurança social de todos os seres humanos. Expressava, textualmente:

\begin{abstract}
A Conferência Geral da Organização Internacional do Trabalho, reunida em Filadélfia em sua vigésima sexta sessão, adota, aos dez de maio de mil novecentos e quarenta e quatro, a presente Declaração, quanto aos itens e objetivos da Organização Internacional do Trabalho e aos princípios que devem inspirar a política dos seus Membros. I A Conferência reafirma os princípios fundamentais sobre os quais repousa a Organização, principalmente os seguintes: a) o trabalho não é uma mercadoria; b) a liberdade de expressão e de associação é uma condição indispensável a um progresso ininterrupto; c) a penúria, seja onde for, constitui um perigo para a prosperidade geral; d) a luta contra a carência, em qualquer nação, deve ser conduzida com infatigável energia, e por um esforço internacional contínuo e conjugado, no qual os representantes dos empregadores e dos empregados discutam, em igualdade, com os dos Governos, e tomem com eles decisões de caráter democrático, visando o bem comum (ILO, 2018c, n/p).
\end{abstract}

A partir da formalização do conceito de Trabalho Decente proposto pela OIT, passavase a verificar a promoção de oportunidades para que homens e mulheres pudessem obter um trabalho produtivo e de qualidade, ou seja, decente, proporcionando condições de liberdade, equidade, segurança e dignidade humana, consideradas condições fundamentais para a 
superação da pobreza, a redução das desigualdades sociais, a garantia da governabilidade democrática e o desenvolvimento sustentável.

\begin{abstract}
A ideia de que o trabalho deve ser a via de acesso a uma vida digna, que está no centro da noção de trabalho decente, é, sem dúvida, muito anterior à formalização dessa noção pela OIT em 1999. Com efeito, ela está no centro da agenda civilizatória do final do século XIX e começo do século XX, que caracterizou a conformação do movimento sindical no âmbito internacional, assim como o surgimento das legislações trabalhistas de muitos países, e a própria criação da OIT (ABRAMO, 2015, p. 19).
\end{abstract}

Do ponto de vista político, Azevedo Neto (2015) lembra que a Declaração da OIT (1998) foi instrumento de consenso, servindo de inspiração para implementar o trabalho decente no mundo e que sua concretização podia ser alcançada na medida em que seus fundamentos passassem a ser respeitados. Para a OIT interessa que o conceito de trabalho decente alcance todos os trabalhadores, inclusive os que estão à margem do mercado de trabalho estruturado ${ }^{3}$.

A noção de Trabalho Decente integra, portanto, a dimensão quantitativa e qualitativa do emprego. Ela propõe não apenas medidas de geração de postos de trabalho e de enfrentamento do desemprego, mas também de superação de formas de trabalho que geram renda insuficiente para que os indivíduos e suas famílias superem a situação de pobreza ou que se baseiam em atividades insalubres, perigosas, inseguras e/ou degradantes. Afirma a necessidade de que o emprego esteja também associado à proteção social e aos direitos do trabalho, entre eles os de representação, associação, organização sindical e negociação coletiva (ABRAMO, 2015, p. 28).

A sua vez, Levaggi (2007, p. 34) sustenta que se trata de "[...] um conceito que busca expressar o que deveria ser, em um mundo globalizado, um bom trabalho ou um emprego digno.”, enquanto que para Brito Filho (2010) trabalho decente pode ser

[...] um conjunto mínimo de direitos do trabalhador que corresponde: à existência de trabalho; à liberdade de trabalho; à igualdade no trabalho; ao trabalho com condições justas, incluindo a remuneração, e que preservem sua saúde e segurança; à proibição do trabalho infantil; à liberdade sindical; e, à proteção contra os riscos sociais (BRITO FILHO, 2010, p. 52).

Vê-se que o conceito atribuído por Brito Filho (2010, p. 52) elenca uma série de direitos considerados constitucionalmente fundamentais e que expressam uma prestação de

\footnotetext{
${ }^{3}$ Durante uma pausa nos mecanismos de mercados de moedas e de capitais, surgiu o movimento estruturado no intuito de resistir aos efeitos perniciosos de uma economia controlada pelo mercado. Formou-se um mercado de trabalho competitivo, e não é exagero dizer que esse sistema foi determinante para a história social do século XIX.
} 
serviços calcada na realização de um bem, no qual, aquele que labora tem o direito de receber. Crivelli (2010, p. 175) procura reforçar a preocupação com o meio ambiente (social e político). Nesse sentido, o autor ensina que Trabalho Decente é "[...] ideia-chave que articula, ao mesmo tempo, a noção do direito ao trabalho, a proteção de direitos básicos, a equidade no trabalho, segurança social, e uma representação dos interesses dos trabalhadores [...] a garantir liberdade e dignidade humana" (CRIVELLI, 2010, p. 175). Essa posição condiz com o que na OIT se tem preconizado, seja em âmbito mundial ou interno, ao lançar campanhas e metas que visem dentre tantos objetivos, ao combate do trabalho escravo e infantil, ao tráfico de pessoas, à redução da pobreza e à desigualdade social, à discriminação no emprego assegurada a liberdade sindical, ao fortalecimento dos atores tripartites ${ }^{4}$ e ao diálogo social como instrumento de governabilidade democrática (AZEVEDO NETO, 2015).

Em 10 de junho de 2008, a OIT publicou a Declaração sobre Justiça Social por uma Globalização Equitativa que veio reafirmar os preceitos do Trabalho Decente reconhecendo-o como elemento central das políticas econômicas e sociais. Assim, da Declaração de 2008 no que tange ao Alcance e Princípios, reverbera-se o disposto no item B da parte 1:

Os quatro objetivos estratégicos são indissociáveis, interdependentes e se reforçam mutuamente. A falta de promoção de qualquer um deles prejudicaria a realização dos demais. Para obter maior impacto, os esforços destinados a promovê-los deveriam compor uma estratégia global e integrada da OIT em benefício do Trabalho Decente. A igualdade entre homens e mulheres e a nãodiscriminação devem ser consideradas questões transversais no marco dos objetivos estratégicos mencionados anteriormente (ILO, 2008, p. 6).

Percebe-se que a consecução de todos os objetivos é crucial e verdadeiro demanda. Os pontos estratégicos dispostos nas referidas declarações certamente inspiraram os esforços da OIT na busca de melhores condições nas Relações de Trabalho, mas, o que se percebe é que o desafio permanece. Com efeito, a definição e a aplicação do conceito de Trabalho Decente exigem compreensão maior, ou seja, necessita de algo além do que já foi apresentado até a realidade atual.

Conforme salientado, as Declarações foram inspiração na consecução dos quatro pilares fundamentais da OIT para a realização de um Trabalho Decente, adotados na Conferência Internacional do Trabalho em 18 de junho de 1998 e insculpidos na Declaração sobre os Princípios e Direitos Fundamentais no Trabalho. Assim, a OIT convencionou chamar

\footnotetext{
${ }^{4}$ A OIT é um Organismo tripartite, ou seja, sua composição é formada por representantes de governos, de organizações de empregadores e de trabalhadores.
} 
de Trabalho Decente, “[...] a) a eliminação do trabalho forçado; b) a erradicação do trabalho infantil; c) o fim da discriminação em matéria de emprego e ocupação e; d) a liberdade sindical e o reconhecimento da negociação coletiva, [...]" (AZEVEDO NETO, 2015, p. 63), que, embora sejam importantes, não demarcam solidamente o que se espera por um Trabalho Decente, calcado no primado da Pessoa Humana sobre o trabalho, no direito ao trabalho e no bem comum.

\section{Acesso ao Trabalho Decente a partir das estratégias promovidas pela OIT}

O Trabalho Decente, cuja noção compreende substancialmente a promoção de igualdade de oportunidades de trabalho para mulheres e homens do mundo, o exercício em condições de liberdade, equidade e segurança, adequadamente remunerado, produtivo e capaz de garantir uma vida digna, é o eixo principal das políticas e programas instituídos pela OIT.

Contudo, não se espera que um Trabalho Decente se limite à produtividade, mas que essa esteja aliada à suficiência, ou seja, a quantidade de trabalho não pode estar dissociada da sua qualidade. $\mathrm{O}$ trabalho para ser compreendido como decente necessita reconhecer sobretudo o valor do trabalhador no desempenho de sua função e como pessoa humana. Um Trabalho Decente precisa ser suficiente, no sentido de proporcionar segurança, proteção contra o desemprego e acesso de oportunidades de trabalho com reconhecimento, relacionalidade e reciprocidade. "O trabalho decente reflete as prioridades da agenda social, econômica e política do sistema internacional, a saber: globalização justa, atenuação da pobreza, segurança, inclusão social, dignidade, diversidade" (ROMITA, 2012, p. 239).

O conceito de Dignidade no Trabalho desenvolve-se sobre quatro pilares, considerados objetivos estratégicos que a OIT estabeleceu para sua consecução: a) respeito às normas internacionais do trabalho, em especial aos princípios e direitos fundamentais do trabalho; b) promoção do emprego de qualidade; c) extensão da proteção social; e, d) fortalecimento do diálogo social.

Tem-se, portanto, que a abrangência do conceito de Trabalho Decente envolve a promoção de oportunidades para mulheres e homens do mundo conseguirem trabalho produtivo e adequadamente remunerado, possibilitando ser exercido em condições de liberdade, equidade e segurança, capaz de garantir uma vida digna (ONU-BR, 2018). Para tanto, necessária a observação de normas eficazes em ambiente democrático de Direito e de diminuição dos custos de transação. 
4.1 Respeito às normas internacionais do trabalho, em especial aos princípios e direitos fundamentais do trabalho

O primeiro pilar do Trabalho Decente abarca em si os princípios fundamentais da OIT. Assim, no que tange à negociação coletiva, essa exprime a existência de relação fundamental entre trabalhadores e empresários para a busca da consolidação de acordos que contemple ambas as partes. Espera-se que na liberdade sindical, seja exercido o direito de ação sindical das negociações coletivas que objetiva considerar necessariamente o debate sobre todas as condições de trabalho.

Desse modo, o fundamento da liberdade sindical e do reconhecimento efetivo do direito de negociação coletiva está diretamente relacionado a outro pilar do Trabalho Decente, o Diálogo Social, que é fruto da liberdade sindical e confere aos trabalhadores a liberdade de expressarem seus desígnios e anseios. Nascimento (2008, p. 65) certifica que "[...] o sindicalismo é fruto da sedimentação de um movimento que percorreu um longo caminho até chegar à fase contemporânea [...]”, ou seja, desde as corporações de ofício, no século XIII, já se pensava numa forma de organização para as Relações de Trabalho.

O segundo fundamento, também integrante do primeiro pilar do Trabalho Decente, almeja a eliminação de todas as formas de trabalho forçado ou obrigatório, e integra todas as "[...] situações em que as pessoas são coagidas a trabalhar através do uso de violência ou intimidação, ou até mesmo por meios mais sutis, como a servidão por dívidas, a retenção de documentos de identidade ou ameaças de denúncia às autoridades de imigração" (ILO, 2019, $\mathrm{n} / \mathrm{p}$ ). No terceiro fundamento, verifica-se a abolição efetiva do trabalho infantil, que representa uma antítese do Trabalho Decente e grave violação dos direitos humanos, pois de acordo com a OIT, na vida adulta, por vias de consequência, demuda-se em trabalho forçado e impacta consideravelmente o desenvolvimento das nações.

Como quarto fundamento identifica-se a eliminação da discriminação em matéria de emprego e ocupação, que apesar das iniciativas para combater a discriminação, alcança níveis mundiais e alastra-se sob os mais diferentes aspectos como sociais, religiosos, raciais e de gênero.

Entretanto, o primeiro pilar da Organização também diz respeito aos princípios e direitos fundamentais do trabalho que, segundo Romita (2012, p. 212), “[...] se aplicam aos trabalhadores considerados em dupla dimensão: como cidadãos na polis e como sujeitos de uma relação de trabalho subordinado.” Para Rosado Iglesias (2004, apud ROMITA, 2012, p. 212), a “[...] impossibilidade de separar o trabalho da pessoa do trabalhador é o primeiro dado sobre 
o qual se baseia o critério objetivo que caracteriza a subordinação.” Nesse sentido, “[...] na execução do contrato de trabalho, o empregado reúne a dupla qualidade de titular de direitos fundamentais que lhe assistem como cidadão e de titular de direitos fundamentais aplicáveis estritamente no âmbito da relação de emprego" (ROMITA, 2012, p. 212).

Os princípios e direitos fundamentais são parâmetros de interpretação para as normas que compõem o Ordenamento Jurídico, incluindo-se as normas voltadas a regulação das Relações de Trabalho.

[...] Ápice da ordem jurídica e expressão suprema dos valores axiológicos fundados sobre a dignidade da pessoa, os direitos fundamentais são dotados de irresistível supremacia jurídica, exercida sobre a integralidade do sistema. Para manter a coerência interna do ordenamento jurídico, é de rigor que os direitos fundamentais se apliquem ao conjunto desse ordenamento, não somente em face do poder público, mas também no âmbito das relações privadas e bem assim no sistema econômico (RODRÍGUEZ PINHEIRO, 2001, apud ROMITA, 2012, p. 213).

Nota-se que os direitos fundamentais sob a ótica do trabalho elevam o patamar da interpretação conferida à valorização do trabalho humano nos âmbitos nacional e internacional, como fundamento da ordem econômica e social.

4.2 A promoção do emprego de qualidade

$\mathrm{O}$ acesso ao trabalho com renda permite ao ser humano a vivência em sociedade e espera-se que esse lhe proporcione os elementos necessários ao seu desenvolvimento, como por exemplo, saúde, moradia, alimentação, vestuário, dentre outros. Contudo, o acelerado processo de crescimento e desenvolvimento global faz persistir, na maioria das vezes, as formas precárias de trabalho que levam à informalidade, um dos fatores de promoção ao trabalho degradante. $\mathrm{O}$ emprego deve ter qualidade superando-se os embates ideológicos, conforme se vê:

O verdadeiro debate de hoje [...] não tem nada a ver com acelerar ou parar a globalização, mas ajudando a criar um tipo de globalização que beneficia mais pessoas, mitiga incertezas e multiplica oportunidades para todos, e isso é justo e verdadeiramente viável para nossa geração e para as gerações futuras (SOMAVÍA, 2014, p. 23).

Promover o emprego de qualidade constitui tarefa difícil de ser executada. Muitas vezes o próprio trabalhador submete-se ao exercício do trabalho degradante e indigno, por ser a única maneira de suprir suas necessidades pessoais e familiares. Quando chega a esse ponto, 
a pobreza seria o menos pior, pois no paradoxo realidade-necessidade, esse último fala mais alto. Acentua Somavía (2014, p. 12) que "[...] não pode haver trabalho decente se não houver trabalho; promover o trabalho produtivo é o elemento concomitante essencial para que haja direitos trabalhistas. $\mathrm{O}$ emprego deve se tornar um objetivo central das políticas nacionais e internacionais de desenvolvimento."

Em 8 de julho de 2003, no discurso proferido aos Ministros da União Africana (Maputo, Moçambique), Somavía (2014, p. 83) assevera que “[...] se aspiramos reduzir a pobreza em $50 \%$, as políticas internacionais e nacionais devem comprometer-se $100 \%$ com emprego.” Afirmou-se:

Parece-me que o grande fracasso do atual modelo de globalização é o emprego: não oferecer oportunidades de trabalho decentes onde as pessoas vivem, ou seja, não gera os empregos de que as pessoas precisam onde elas precisam. A falta de oportunidades resultantes - o déficit no trabalho decente - gera ressentimento, raiva e frustração. É um terreno fértil para pobreza, extremismo e medo, e empurra as pessoas para o beco do mercado que é a economia informal. O déficit no trabalho decente destrói gradualmente a esperança do povo de ter um futuro melhor e fé nas instituições democráticas. E isso nos afeta a todos. Eu acho que não haveria rejeição da globalização se houvesse emprego pleno com condições de trabalho decentes (SOMAVÍA, 2014, p. 126).

Portanto, a promoção do emprego de qualidade é sinônimo de Trabalho Decente, é pilar essencial à manutenção da vida do trabalhador e; nele, consiste sua dignidade. Destaca-se ainda que a Resolução final da Assembleia Geral da ONU, adotada em setembro de 2005, em seu artigo 47 ao tratar do tema 'Emprego', definiu o Trabalho Decente como objetivo nacional e internacional. A referida Resolução foi assinada por 150 Chefes de Estado e Governo reunidos na Sede das Nações Unidas em Nova Iorque, de 14 a 16 de setembro de 2005, nos seguintes termos:

Apoiamos vigorosamente uma globalização justa e como parte de nossos esforços para alcançar os Objetivos de Desenvolvimento do Milênio, tomamos a decisão de tornar as metas do emprego pleno e produtivo e do trabalho digno para todos, incluindo as mulheres e os jovens, um objetivo fulcral das nossas políticas nacionais e internacionais pertinentes, bem como das nossas estratégias de desenvolvimento nacionais, incluindo as estratégias de redução da pobreza. Estas medidas devem abranger, também, a eliminação das piores formas de trabalho infantil, em conformidade com a definição da Convenção $\mathrm{N}^{\circ} 182$ da Organização Internacional do Trabalho, bem como do trabalho forçado. Tomamos também a decisão de garantir o pleno respeito pelos princípios e direitos fundamentais do trabalho (ONU, 2005, p. 16). 
Percebe-se que a partir desse momento a ONU adotou o Trabalho Decente como elemento estratégico para a diminuição da pobreza e de consecução dos Objetivos de Desenvolvimento do Milênio. Da mesma forma observa-se no artigo $1^{\circ}$ da Declaração de Mar del Plata (2005), quando preceitua “[...] um lugar central na agenda hemisférica, reconhecendo assim o papel essencial da criação de trabalho decente [...]." (MTE/PNTD, 2010, p. 5). Tem-se assim, expressamente a deferência ao direito ao trabalho. ${ }^{5} \mathrm{O}$ Trabalho decente é visto, então, como difusor da inclusão social.

\subsection{A extensão da proteção social}

Pressupõe-se que a extensão da proteção social se dê além das esferas do ambiente de trabalho. Para tanto, a OIT adotou na Conferência Internacional do Trabalho de 2012, a Recomendação n. 202, que estabelece Pisos Nacionais de Proteção Social e proporciona orientações para que os Estados-membros possam construí-los (ILO, 2019, n/p). “[...] O trabalho é essencial para o bem-estar de indivíduos, famílias, comunidades e sociedades. Portanto, o acesso ao trabalho constitui uma reivindicação política chave.” (SOMAVÍA, 2014, p. 90). Dessa maneira, concebe-se que a Recomendação n. 222 constitui-se em uma das normas internacionais do trabalho que visa assegurar nível adequado de proteção social, notadamente à população idosa, aposentada e com carência de renda para suprir as suas necessidades.

A OIT empreende para a consecução de uma agenda universal e por isso concentra suas estratégias para o desenvolvimento de trabalho digno e vida digna. Nesse contexto, sua atenção volta-se, também, às questões relacionadas às pessoas com deficiência, pois entre elas as taxas de pobreza, desemprego e subemprego tendem a ser excessivas. Empreendem-se, também, esforços voltados para a juventude:

A juventude é o agente de mudança para um mundo melhor: exige mais equidade dentro das nações e também entre elas. Um jovem produtivo e motivado ajuda a aumentar a prosperidade econômica: sua criatividade e sua capacidade de inovação podem gerar fontes sustentáveis de crescimento e

\footnotetext{
${ }^{5}$ No ano de 2006, a partir da recomendação do Conselho Econômico e Social (CES) da ONU ao Sistema das Nações Unidas para apoiar e financiar programas de geração de emprego, o Trabalho Decente ganhou forças na sua implementação e, em 04 de maio do mesmo ano, após consultas às organizações de empregadores e trabalhadores, durante a XVI Reunião Regional Americana, realizada em Brasília; o Brasil assinou Memorando de Entendimentos no qual se previu o estabelecimento de Programa Especial de Cooperação Técnica e lançou-se, oficialmente, a Agenda Nacional de Trabalho Decente (ANTD) que estabelece as seguintes prioridades: gerar mais e melhores empregos, com igualdade de oportunidades e de tratamento; erradicar o trabalho escravo e eliminar o trabalho infantil, principalmente as piores formas; e fortalecer os atores tripartites e o diálogo social como um instrumento de governabilidade democrática (ONU-BR, 2018; COSTA, 2010, n/p).
} 
emprego, especialmente emprego "Verde" que contribui para o meio ambiente ser sustentável (SOMAVÍA, 2014, p. 101).

A proteção social consiste em combater as vulnerabilidades e os imprevistos que atingem as pessoas, retirando-as do mundo do trabalho. Prova disso é o desemprego, considerado um flagelo que ameaça à paz social e que nenhum País está isento, pois dificulta os esforços empreendidos para mitigar a pobreza, a miséria e toda e qualquer tentativa de reforma econômica, político ou social. Nesse sentido, acentua Romita (2012, p. 316) que “[...] os seres humanos são, como é evidente, desiguais entre si. Não há dois seres iguais. Do ponto de vista jurídico, o que importa é fixar os critérios aptos a propiciar tratamento igual ou desigual a seres situados em posições jurídicas iguais ou desiguais." Portanto, faz-se imprescindível medidas voltadas a grupos vulneráveis com vistas a sua proteção e inserção no trabalho, sendo a proteção social e o emprego componentes essenciais na agenda para o benefício do povo.

\subsection{Diálogo social}

Alcançar maior consenso junto a temas que perpassam o mundo do trabalho é um dos objetivos desse pilar do Trabalho Decente, formado na relação tripartite (trabalhadores, empregadores e governo) que, juntos, se manifestam sobre temas relacionados ao mundo trabalho. O Diálogo Social consiste na participação efetiva das partes interessadas, contudo, sua implantação precisa acontecer de maneira democrática e desburocratizada, a fim de estabelecer vínculos comprometidos com sua efetiva realização.

À medida que assuntos que preocupam os parceiros sociais se relacionem cada vez mais com os acontecimentos econômicos internacionais ou sofram seus efeitos, elas ocuparão um espaço crescente no diálogo social em nível nacional e local. E esse diálogo se tornará cada vez mais importante a nível internacional, onde a OIT continua sendo o principal fórum de debates dessa natureza. $\mathrm{O}$ trabalho desenvolvido pela OIT neste campo tem como objetivo fortalecer as capacidades das organizações de trabalhadores e empregadores, bem como dos governos, para analisar essas questões e promover o diálogo através do desenvolvimento de instituições e mecanismos em nível nacional e internacional. Para realizar esta tarefa, e quando considerarem apropriado, os constituintes tripartidos da OIT interagem com outros atores da sociedade civil (SOMAVÍA, 2014, p. 113).

Para a OIT, o diálogo social abarca todos os tipos de negociação, consulta e troca de informações sobre questões relacionadas à política econômica e social. Além de promover 
consensos e participação democrática dos atores do mundo trabalho, é instrumento fundamental para a promoção da justiça social. A OIT tem uma definição ampla de diálogo social:

[...] que reflete a extensa variedade de processos e práticas encontrados em diferentes países. Segundo essa definição básica, o diálogo social inclui todo tipo de negociações e consultas ou simplesmente, a mera troca de informações entre representantes de governos, empregadores e trabalhadores, sobre questões de interesse comum relacionadas a políticas econômicas e sociais (ISHIKAWA, 2004, p. 3).

Pode-se dizer que o diálogo social é meio facilitador para assegurar a interação construtiva e compromissada com o consenso entre distintos interlocutores na sociedade, podendo ser informal ou institucional, ou ainda combinação de ambos (ISHIKAWA, 2004). Somavía (2014, p. 182) acentua: “[...] eu acredito firmemente que o diálogo sempre é possível se tivermos coragem e imaginação para encontrar esse equilíbrio essencial entre o estado, os mercados e a sociedade que exige a democracia aberta e participativa de hoje." Políticas equilibradas e escuta ativa representam caminhos para se lograr êxito frente às crises vivenciadas pela sociedade, em especial, as relacionadas ao trabalho; assim, o diálogo é o caminho:

Na OIT, acreditamos no diálogo. Acreditamos que o diálogo é a base da estabilidade social. Acreditamos que o entendimento entre as organizações de Trabalhadores e empregadores desempenham um papel essencial, tanto dentro das empresas quanto na sociedade. E acreditamos que através do diálogo nacional e global podem surgir uma forma mais inclusiva de globalização (SOMAVÍA, 2014, p. 304).

O diálogo social possui o condão de interligar-se e de relacionar-se com os demais pilares da OIT, além de outros objetivos sociais, de modo que isso fortalece a participação e a representatividade dos interlocutores sociais. A OIT fomenta o diálogo social por meio de suas convenções e recomendações, fazendo crer que se trata de mecanismo eficaz de participação e por isso essencial à democracia. Tem-se que a OIT, na sua formulação de programas voltados para o Trabalho Decente, anseia por um diálogo social ativo:

Um diálogo dentro dos governos para encontrar o equilíbrio necessário. Um diálogo social entre empregadores e trabalhadores, nas empresas e nos setores econômicos, para resolver disputas e conciliar interesses. Um diálogo tripartido, amplo e transparente entre governos, empregadores e trabalhadores para contribuir com a formulação de políticas nacionais. Um diálogo político para fortalecer a democracia e proporcionar estabilidade e continuidade ao longo do tempo às estratégias de crescimento, investimento e emprego 
decente. Um diálogo internacional para fortalecer a segurança e a prosperidade de todos. Em suma, uma cultura de diálogo (SOMAVÍA, 2014, p. 707).

Assim, concebe-se que, por meio do diálogo social, as práticas sociais, ou melhor, as políticas; configuram-se mais legítimas, devido à participação efetiva dos atores sociais, seja nos processos decisórios ou na reflexão de seus pontos de vista e resultados. Além dos quatro pilares, bem como dos princípios fundamentais estabelecidos pela OIT, há que se considerar os princípios contidos na Declaração de 1944 dos quais repousa a Constituição da OIT para a efetivação do diálogo social construtivo e efetivo.

A OIT coopera com vários países que estão reformando o mercado de trabalho, a proteção social e o treinamento técnico, a fim de melhorar a capacidade de aplicar esses padrões. No entanto, para a OIT, a reforma deve incluir a criação de empregos, o que implica empresas sustentáveis e capital inicial para empresas produtivas e inovadoras que criam no diálogo social (SOMAVÍA, 2014, pp. 177-178).

Sob a aprovação da Conferência Internacional do Trabalho, instância máxima da OIT, a Agenda Nacional de Trabalho Decente, em 2008, viu-se fortalecida pela Declaração sobre Justiça Social para uma Globalização Equitativa. Considerada a terceira mais importante declaração de princípios e políticas desde a Constituição da OIT de 1919, a Declaração reafirmou valores e expressou a visão contemporânea da OIT na era da globalização (ILO, 2008, p. 1-17).

Em decorrência das discussões ocorridas na XVI Reunião Regional Americana da OIT, representantes de governos, organizações sindicais e de empregadores, propuseram uma década dedicada à promoção do Trabalho Decente com vistas à redução da pobreza até o ano de 2015. Era criada a Agenda Hemisférica de Trabalho Decente (AHTD), cujas políticas de implementação constam no documento Trabalho Decente nas américas: uma agenda hemisférica, 2006-2015.

A OIT coloca em prática o conceito de Trabalho Decente mediante assistência técnica a seus membros e parceiros na implementação das normas internacionais do trabalho, bem como, pela implementação de programas e projetos nas áreas de emprego, proteção e diálogo social e no desenvolvimento de pesquisas e estudos relacionados aos diversos temas do mundo do trabalho (ONU-BR, 2018).

Na 97 Reunião da Conferência Internacional do Trabalho, ocorrida em junho de 2007, realizada em Genebra, o conceito de Trabalho Decente foi relacionado intrinsecamente ao 
conceito de desenvolvimento sustentável, em seus três pilares (econômico, social e ambiental). A ideia básica dessa relação é enfatizar o diálogo social e destacar a relação mútua entre trabalhadores, empregadores e suas organizações com vistas ao apoio na implementação de empresas sustentáveis. Importa dizer que as empresas sustentáveis são uma condição para o Trabalho Decente, e, em contrapartida, o Trabalho Decente se faz condição necessária para a sustentabilidade das empresas. Abramo (2015, p. 42) acentua que tais documentos “[...] expressam um consenso tripartite em relação à necessidade de proteger o emprego e as empresas sustentáveis, fortalecer os mecanismos de proteção social e garantir o respeito aos direitos no trabalho no contexto da crise econômica internacional."

Por ocasião da $102^{\mathrm{a}}$ Reunião da Conferência Internacional do Trabalho, em junho de 2013, aprovou-se Resolução cuja proposta era a transversalização da perspectiva do desenvolvimento sustentável em todos os programas da OIT. Tratava-se da Resolução relativa ao emprego e à proteção social no novo contexto demográfico reconhecendo que transições demográficas repercutem nos mercados de trabalho e nos sistemas de proteção social. (ILO, 2013a, n/p).

Na ocasião, o Diretor Geral da OIT, ao se referir às iniciativas relativas ao futuro do trabalho, assinalou que "[...] é necessário um exame inovador acerca do local do trabalho em nossas vidas e da sociedade. Trata-se de um marco de opções políticas e será apropriado para a celebração do $100^{\circ}$ aniversário da OIT" (ILO, 2013a, n/p). Entre os anos de 2013 e 2014 foram desenvolvidas ações locais voltadas para a realização do Trabalho Decente:

[...] foram realizadas oito oficinas nas cidades-sede da Copa, para discussão e organização de ações locais voltadas a garantir a geração de emprego e trabalho decente. As atividades culminaram com a realização, em 15 de maio de 2014, de solenidade de lançamento da Campanha e assinatura do Compromisso Nacional pelo Emprego e Trabalho Decente na Copa do Mundo Fifa Brasil 2014, na presidência da República (DIEESE, 2015, p. 19).

Em setembro de 2015, foi lançada a Agenda 2030 para o Desenvolvimento Sustentável, que reafirma, para os próximos quinze anos, o Trabalho Decente enquanto instrumento indispensável para a promoção do desenvolvimento sustentável:

A Agenda 2030 amplia os objetivos que estavam contemplados nos ODMs, e o alcance de suas metas. Tem um caráter universal, ou seja, diz respeito a todos os países e não apenas àqueles em desenvolvimento. É muito mais ambiciosa em relação aos objetivos de superação da pobreza, ao definir como metas, até 2030, a erradicação da extrema pobreza 'para todas as pessoas e em todo o mundo' e a redução pela metade da proporção de homens, mulheres e 
crianças de todas as idades que vivem em situação de pobreza em todas as suas dimensões (ODS n. 1); além disso, introduz de forma clara o objetivo de reduzir a desigualdade nos países e entre eles (ODS n. 10) e, explicitamente, como parte do ODS n. 8, a promoção de 'um crescimento econômico sustentável, inclusivo e continuado' e do 'emprego pleno e produtivo e trabalho decente para todos' (ABRAMO, 2015, p. 44).

A Agenda 2030 visa Plano de ação arrojado tratando dos chamados "5 P' s", ou seja, um Plano para as Pessoas, o Planeta, a Prosperidade, a Paz e a Parceria; além disso, traça 17 Objetivos de Desenvolvimento Sustentável (ODS) e 169 metas demonstrando a ambição da Agenda de caráter Universal. Constituindo projeto com intensas metas, a Declaração apresenta, em uma de suas primeiras notas introdutórias, (3), os seguintes termos:

3. Nós resolvemos, entre agora e 2030, acabar com a pobreza e a fome em todos os lugares; combater as desigualdades dentro e entre os países; construir sociedades pacíficas, justas e inclusivas; proteger os direitos humanos e promover a igualdade de gênero e o empoderamento das mulheres e meninas; e assegurar a proteção duradoura do planeta e seus recursos naturais. Resolvemos também criar condições para um crescimento sustentável, inclusivo e economicamente sustentado, prosperidade compartilhada e trabalho decente para todos, tendo em conta os diferentes níveis de desenvolvimento e capacidades nacionais (UNIC Rio, 2015, n/p).

Aspirando o acesso a um mundo equitativo e universal, a Agenda 2030 pauta-se nos princípios esculpidos na Carta das Nações Unidas, que inclui o respeito integral ao Direito Internacional. Sob tal ímpeto, fundamenta-se em documentos como a Declaração Universal dos Direitos Humanos, os tratados internacionais de direitos humanos, a Declaração do Milênio e os resultados da Cúpula Mundial de 2005, além de outros instrumentos como a Declaração sobre o Direito ao Desenvolvimento (UNIC Rio, 2015, n/p).

A exemplo disso, a Agenda 2030 apresenta o objetivo $8^{\circ}$ que é explícito nas intenções tangentes ao Trabalho Decente: "Promover o crescimento econômico sustentado, inclusivo e sustentável, emprego pleno e produtivo e trabalho decente para todos. São estratégias voltadas à promoção de políticas orientadas ao apoio de atividades produtivas, geração de emprego decente, com incentivo à formalização e crescimentos das micro, pequenas e médias empresas, inclusive por meio de acesso a serviços financeiros, melhorando progressivamente, até 2030, todas as formas de trabalho e emprego degradantes" (UNIC Rio, 2015, pp. 26-27).

Evidentemente, a Agenda 2030 estabelece metas estrategicamente idealizadas e de cunho universal. Conforme expõe Chinoy (2012, p. 418), “[...] não apenas instrumentos, máquinas e outros implementos, mas também os conhecimentos e a habilidade acumulados 
necessários à utilização de quaisquer instrumentos disponíveis. Sem a perícia necessária, a maquinaria complexa tem pouco valor; [...]. Portanto, implementos específicos utilizados pelo homem (sic), como o conhecimento tradicional, devem ser incluídos. Inovações nas relações trabalhistas devem, também, ser introjetadas:

O futuro do trabalho exige modelos de contratação flexíveis o suficiente para se ajustarem às mudanças na realidade do mercado. $\mathrm{O}$ aumento crescente do teletrabalho, por exemplo, que pode trazer inúmeros benefícios para o trabalhador, não deve cobrar um preço em termos de formalização e proteção social. O trabalho intermitente, aquele que oscila muito em função da natureza de certas atividades, tampouco deve se dar à margem do mercado formal. Formas atípicas de emprego não devem ser, em suma, sinônimo de precarização (ILO, 2018d, p. 13).

A preocupação com o futuro do trabalho demanda o aprimoramento de políticas públicas, marcos legais e contínuo e aprofundado diálogo social. Stelzer (2018, p. 23) recorda que “[...] O sistema comercial engendrado [...] foi complacente com os países que escreveram sua história, mas não ofertou indulgências àqueles que estavam à margem, a exemplo dos países da América Latina." Portanto, o futuro do trabalho vai além do intenso esforço e comprometimento da sociedade.

Quanto aos diálogos empreendidos durante a $104^{\mathrm{a}}$ Conferência Internacional do Trabalho, o pesquisador Jacques Marcovitch relembrou pontos do relatório da OIT produzido em 2012, como um dos mais agudos e pertinentes acerca da crise mundial de 2008: “[...] Poderia estender-me aqui sobre os distúrbios sociais na União Europeia, previstos pela OIT naquele ano ou sobre o aumento de 3,4\% no lucro das empresas da área do G20, enquanto os salários médios subiam apenas $2 \%$ e os investimentos recuavam incessantemente.”(ILO, 2018d, p. 15). Durante o diálogo, Marcovitch apresentou dados estatísticos relacionados ao Brasil que, apesar de figurar entre os países com maior sucesso na redução da exclusão social, ainda permanecia com níveis de crescentes desigualdades. "[...] Embora tenha reduzido a pobreza extrema, o País continua muito desigual. Ainda somos um país em que os $40 \%$ mais pobres têm $12 \%$ da renda total, enquanto os mais aquinhoados têm 56\% dessa renda." (ILO, 2018d, p. 15). Evidentes, pois, os desafios futuros:

Estes dados naturalmente refletem assimetrias crescentes no universo do trabalho e impactarão o cenário futuro que a OIT vem construindo para melhor formular as suas projeções. Para esta construção do futuro empreenderemos dois diálogos. O primeiro aborda o Desenvolvimento Sustentável: Desafios e Oportunidades para o Futuro do Trabalho. Questiona-se, cada vez mais, o princípio econômico que estabelece que o desenvolvimento depende 
principalmente do crescimento das taxas do PIB per capita (ILO, 2018d, p. $15)$.

Nesse contexto, o Trabalho Decente ganha proporções maiores, quais sejam, de estar a ele vinculado o reconhecimento dos limites do Planeta em absorver os impactos do crescimento dos padrões atuais de consumo. “[...] Uma distância mais do que secular já nos separa da Revolução Industrial. Sendo “[...] necessário, porém, nesta segunda década do Século XXI, muita imaginação das forças que protagonizam o mundo do trabalho na busca de uma doutrina que oriente o futuro.”, afirma Marcovitch (ILO, 2018d, p. 16). É crucial estabelecer formas dignas e decentes de trabalho. Certamente houve avanços, porém, as propostas de alternativas para repensar a fonte de geração dos empregos no futuro são menores que as dúvidas e os questionamentos apresentados.

\section{Conclusão}

Do surgimento da OIT e especialmente a partir da incorporação da Declaração da Filadélfia aos princípios fundantes da Organização, tornou-se notória a garantia de condições justas e favoráveis laborais para o trabalhador, incluindo desde remuneração mínima, saúde plena, segurança no exercício da função, até o status da dignidade humana na atividade laboral. Entre a previsão da norma jurídica e o cotidiano, contudo, ainda se abre um "fosso" de imensas dimensões.

Dignidade é a característica elementar que eleva a Pessoa à categoria de Humana, enquanto ser dotado de valores morais e espirituais, diferenciando-a de outros seres animados. O Trabalho Digno considera a Pessoa Humana em toda sua integridade e permite o crescimento subjetivo do Ser, apoiando esse processo nos horizontes de uma sociedade íntegra. Não se trata, portanto, de extrair do Ser Humano a força de trabalho mediante pagamento, mas de cooperar no exercício laboral rumo ao crescimento suprassensível da coletividade.

A realidade e suas novas relações trabalhistas trouxeram questionamentos severos sobre a eficácia das conquistas acerca do Trabalho Decente no plano prático. Contemporaneamente, a degradação das relações laborais - a exemplo das que se desenvolvem por aplicativo de entrega de refeições ou de transporte privado - tem exigido reflexão sobre verdadeiros retrocessos que a sociedade dita moderna enfrenta para concretizar a Dignidade.

As diretrizes da OIT pautadas pelo respeito às normas internacionais do trabalho (em especial, aos princípios e direitos fundamentais do trabalho), pela promoção do emprego de 
qualidade, pela extensão da proteção social e pelo fortalecimento do diálogo social passam pela conscientização tripartite dos agentes envolvidos. Não é possível criar um ordenamento que assegure Trabalho Digno quando a sociedade não dignifica a si mesmo. Há diversas situações de opressão às quais as classes populares se submetem, sem que se lance o alerta da submissão a condições não dignas. Com efeito, a verdadeira liberdade é sempre coletiva e se realiza também no outro.

Reconhecer no outro um pouco de si mesmo é a mudança paradigmática que se impõe, o que permitiria trazer condições de dignidade à coletividade. Mas, enquanto as relações laborais utilizarem somente o livre mercado e a imposição das condições econômicas na qualidade de parâmetros não será possível construir o pretenso diálogo social. O Trabalho Decente é o ponto de convergência dos objetivos estratégicos da OIT - como o reconhecimento efetivo do direito de negociação coletiva, a eliminação do trabalho forçado, a abolição do trabalho infantil, a eliminação da discriminação - mas, sempre, cumpre registrar que as relações não são entre Estados; mas, sempre e acima de tudo, entre pessoas.

\section{Referências}

AZEVEDO NETO, Platon Teixeira de. O trabalho decente como um direito humano. São Paulo: LTr, 2015.

ABRAMO, Laís. Uma década de promoção do trabalho decente no Brasil: uma estratégia de ação baseada no diálogo social. Organização Internacional do Trabalho - Genebra: OIT, 2015. Disponível em: https:/www.ilo.org/wcmsp5/groups/public/---americas/---ro-lima/--ilo-brasilia/documents/publication/wcms_467352.pdf Acesso em: 23. jun. 2020.

BRITO, Rildo Albuquerque Mousinho de. A Organização Internacional do Trabalho e seus esforços pela implementação do trabalho decente. In: Revista do Tribunal Regional do Trabalho da 1ª Região. Rio de Janeiro, Centro de Estudos de Legislação Fiscal, 1970. Referência: v. 23, n. 50, p. 35-41, jul./dez., 2011.

BRITO FILHO, José Cláudio Monteiro de. Trabalho decente: análise jurídica da exploração do trabalho: trabalho escravo e outras formas de trabalho indigno. 3. ed. São Paulo: LTr, 2013.

CHINOY, Ely. Sociedade: uma introdução à sociologia. Tradução de Octavio Mendes Cajado. São Paulo: Editora Cultrix, 2012.

COSTA, Mônica Oliveira da. Trabalho decente segundo estudos da Organização Internacional do Trabalho. In: Revista Jus Navegandi, ISSN 1518-4862, Teresina, ano 15, n. 2649, 2 out. 2010. Disponível em: https://jus.com.br/artigos/17550 Acesso em: 19 dez. 2018. 
CRIVELLI, Ericson. Direito internacional do trabalho contemporâneo. São Paulo: LTr, 2010 .

DIEESE (Departamento Intersindical de Estatística e Estudos Socioeconômicos). Anuário do sistema público de emprego, trabalho e renda 2015. Livro 7, Indicadores da Agenda de Trabalho Decente. DIEESE: São Paulo, 2015. Disponível em:

https://www.dieese.org.br/anuario/2015/sistPubLivreto7TabalhoDecente.pdf Acesso em: 24 jun. 2020.

EXAME. 1 em cada 4 brasileiros vive com menos de R\$ 420 por mês, diz IBGE. Disponível em: https:/exame.abril.com.br/economia/1-em-cada-4-brasileiros-vive-commenos-de-r-420-por-mes-diz-ibge/ Acesso em: 03 jun. 2020.

IANNI, Octavio. A era do globalismo. 2. ed. Rio do janeiro: Civilização Brasileira, 1996.

ILO - International Labour Organization. O que é trabalho forçado? Brasília. (2019). Disponível em: https://www.ilo.org/brasilia/temas/trabalho-escravo/WCMS_393058/lang-pt/index.htm Acesso em: 27 jul. 2020. (Não paginado - n/p)

ILO - International Labour Organization. História da OIT. (2018a). Disponível em: https://www.ilo.org/global/about-the-ilo/history/lang--en/index.htm Acesso em: 18 jul. 2020. (Não paginado $-\mathrm{n} / \mathrm{p}$ )

ILO - International Labour Organization. David A. Morse. (2018b). Disponível em: https://www.ilo.org/global/about-the-ilo/how-the-ilo-works/ilo-director-general/formerdirectors-general/WCMS_192712/lang--en/index.htm Acesso em: 18 jul. 2020. (Não paginado $-\mathrm{n} / \mathrm{p}$ )

ILO - International Labour Organization. Declaração sobre os objetivos e propósitos da Organização Internacional do Trabalho (DECLARAÇÃO DE FILADÉLFIA). (2018c). Disponível em:

http://www.ilo.ch/dyn/normlex/en/f?p=1000:62:0::NO:62:P62_LIST_ENTRIE_ID:2453907: NO\#declaration Acesso em: 18 jul. 2020. (Não paginado - n/p)

ILO - International Labour Organization. Futuro do Trabalho no Brasil: Perspectivas e Diálogos Tripartites. Publicado em 26 de abril de 2018. [ISBN] 978-92-2-830943-0 (web pdf). (2018d). Disponível em: https://www.ilo.org/wcmsp5/groups/public/---americas/---rolima/---ilo-brasilia/documents/publication/wcms_626908.pdf Acesso em: 1. jun. 2020.

ILO - International Labour Organization. 102 ${ }^{\mathrm{a}}$ Conferência Internacional del trabajo. (Comunicado de prensa - 21 de junho de 2013. (2013a). Disponível em:

https://www.ilo.org/ilc/ILCSessions/previous-sessions/102/mediacentre/news/WCMS_216663/lang--es/index.htm Acesso em: 24 jun. 2020. (Não paginado $\mathrm{n} / \mathrm{p})$

ILO - International Labour Organization. Declaração da OIT Sobre Justiça

Social para uma Globalização Justa. (Adoptada pela Conferência Internacional do Trabalho na $97^{\mathrm{a}}$ Sessão, Genebra, 10 de Junho de 2008). Brasília. (2008). Disponível em: https:/www.ilo.org/wcmsp5/groups/public/---americas/---ro-lima/---ilobrasilia/documents/genericdocument/wcms_336918.pdf Acesso em: 18. jun. 2020. 
ISHIKAWA, Junko. Aspectos clave del Diálogo Social Nacional: un documento de referencia sobre el Diálogo Social. Genebra, Oficina Internacional del Trabajo, 2004.

LEVAGGI, Virgílio. O que é o trabalho decente? In: Revista ALJT. São Paulo, ano 1, n. 1, p. 34, jun. 2007.

MATTOS, Fernando Augusto Mansor de. Emprego e trabalho do pós-segunda guerra à crise deflagrada pela falência do subprime. In: Nexus Econômicos. CME-UFBA, vol. VI, n. 10, junho de 2012, pp. 59-82.

MTE (MINISTÉRIO DO TRABALHO E EMPREGO. PNTD - Plano nacional de trabalho decente. Gerar Trabalho Decente para Combater a Pobreza e as Desigualdades Sociais. Esplanada dos Ministérios, Brasília, 2010.

NASCIMENTO, Amauri Mascaro. Compêndio de direito sindical. São Paulo: LTr, 2008.

ONU. Organização das Nações Unidas. Documento Final da Cimeira Mundial 2005. $60^{\mathrm{a}}$ Sessão. 20 set. 2005. Disponível em:

https:/www.unric.org/html/portuguese/summit2005/World\%20Summit\%20OutcomeptREV.pdf Acesso em: 23 jun. 2020.

ONU-BR. Organização das Nações Unidas no Brasil. OIT Organização Internacional do Trabalho. (2018). Disponível em: https://nacoesunidas.org/agencia/oit/ Acesso em: 22. jun. 2020.

RODGERS, Gerry. El trabajo decente como una meta para la economía global. In: Boletín técnico interamericano de formación profesional. Formación profesional, productividad y trabajo decente. Montevideo, OIT/Cinterfor, n. 153, p. 9-28, oct. 2002.

ROMITA, Arion Sayão. Direitos fundamentais nas relações de trabalho. São Paulo: LTr, 2005.

ROMITA, Arion Sayão. Direitos fundamentais nas relações de trabalho. 4. ed. rev. e aumentada. São Paulo: LTr, 2012.

SOMAVÍA, Juan. El trabajo decente. Una lucha por la dignidad humana. Santiago, Organización Internacional del Trabajo, 2014.

STELZER, Joana. Direito do comércio internacional: do Free Trade ao Fair Trade. Curitiba: Juruá, 2018.

SÜSSEKIND, Arnaldo. Convenções da OIT. 2. ed. 1998. São Paulo: LTr, 1998.

UNIC Rio. Transformando Nosso Mundo: A Agenda 2030 para o Desenvolvimento Sustentável. Objetivos de desenvolvimento sustentável. Traduzido pelo Centro de Informação das Nações Unidas para o Brasil (UNIC Rio), última edição em 13 de outubro de 2015. Disponível em: https://sustainabledevelopment.un.org Acesso em: 21. dez. 2018. (Não paginado $-\mathrm{n} / \mathrm{p}$ ) 
WANDELLI, Leonardo Vieira. O direito fundamental ao conteúdo do próprio trabalho: uma reconstrução normativa do direito ao trabalho. In: Revista Espaço Jurídico: Espaço Jurídico Journal of Law [EJJL]/Universidade do Oeste de Santa Catarina. v. 17, n. 3, p. 1013-1036, set./dez. 2016. Joaçaba: Editora Unoesc, 2016.

Data de recebimento: 02.05.2021

Data de aprovação: 20.07.2021 